\title{
Significance of Ras Signaling in Cancer and Strategies for its Control
}

\author{
Arun Bahadur Gurung, $\mathrm{MSc}^{1}$ and Atanu Bhattacharjee, $\mathrm{PhD}^{2}$ \\ 1. Researcher; 2. Assistant Professor, Computational Biology Laboratory, Department of Biotechnology \& Bioinformatics, North Eastern Hill University, Shillong, India
}

DOI: http://doi.org/10.17925/OHR.2015.11.02.147

\begin{abstract}
Ras is a GTP-binding protein and is the most widely studied oncoprotein. To achieve its biological activity, it must undergo post-translation modification. Ras acts as a typical molecular switch. The GTP-bound Ras can activate several downstream effector pathways. Ras signaling regulates many important physiologic processes within a cell, such as cell cycle progression, survival, apoptosis, etc. Several studies have found mutation in Ras or its effectors in various types of tumors. Therefore, Ras or its downstream effectors can be attractive drug targets against various types of tumors in cancer therapeutics. Some therapeutic agents against Ras effectors, such as Raf, MEK1/2, PI3K, AKT etc., have successfully managed to enter into phase I and II trials. This targeted drug design could be envisaged in mainly four ways, such as prevention of Ras-GTP formation, covalent locking of the GDP-bound Ras, inhibition of Ras-effector interactions, or impairment of post-translational modification of Ras. In this review we summarize the normal Ras signaling as well its aberrant signaling in tumors and various strategies to inhibit Ras signaling.
\end{abstract}

\section{Keywords}

Ras signaling, oncoprotein, effectors, apoptosis

Disclosure: Arun Bahadur Gurung, MSc, and Atanu Bhattacharjee, PhD, have nothing to disclosure in relation to this article. No funding was received in the publication of this article.

Open Access: This article is published under the Creative Commons Attribution Noncommercial License, which permits any noncommercial use, distribution, adaptation, and reproduction provided the original author(s) and source are given appropriate credit.

Received: May 14, 2015 Accepted: October 21, 2015 Citation: Oncology \& Hematology Review, 2015;11(2):147-52

Correspondence: Atanu Bhattacharjee, PhD, Computational Biology Laboratory, Department of Biotechnology and Bioinformatics, North Eastern Hill University, Shillong-793022, India. E: atanubioinfo@gmail.com

$\mathrm{H}$-Ras, K-Ras, and N-Ras are the main members of Ras superfamily, which bind small molecules GTP and GDP interchangeably and can hydrolyze GTP to GDP. The Ras superfamily consists of more than 150 proteins and these can be classified under at least five sub-families viz: the Ras, Rab, Rho, Ran, and Arf families. ${ }^{1}$ Ras oncoproteins act as typical molecular switch by alternately binding to GTP and GDP molecule and has intrinsic GTPase activity. It remains in an active state when bound to GTP and switches to an inactive state by binding to GDP and thus controls the expression of the downstream genes. Ras signaling is an important intracellular signaling pathway that plays a role in cellular proliferation and differentiation, survival, and gene expression..$^{2-4}$ Ras oncoprotein has also been implicated in the development of cancer by either having increased intensity or prolonged signaling mechanism. ${ }^{5}$ This may happen either due to a mutation in the Ras-GTPase domain, which renders it constitutively inactive (GDP-bound state), or due to activating mutation in growth factor receptors that act upstream of Ras or due to aberrant RAS effector activation. Due to the elevated level of Ras signaling in tumor growth and progression, Ras proteins and its downstream effector proteins may serve as promising therapeutic targets against cancer. In this review article we shed light on normal Ras signaling as well as its aberrant signaling in tumors and proposed various strategies for its inhibition.

\section{Normal Ras Signaling Pathways}

The three human RAS genes encode four proteins with a size of $\sim 21$ KDa: H-Ras, N-Ras and the splice variants K-Ras4A and K-Ras4B. A newly synthesized Ras protein is a soluble cytoplasmic protein, which needs to undergo post-translation modifications to associate with particular lipid membrane. These modifications occur at the carboxyl terminal 'CAAX' box (denoting amino acid sequence cysteine-aliphatic-aliphatic- $X$ residue). The first step involved is the attachment of 15 carbon farnesyl to the cysteine residue of the 'CAAX' box. ${ }^{6}$ Next, an endopeptidase Rce 1 cleaves off three terminal amino acid residues and the resulting isoprenylated cysteine residue is methylated by the isoprenylcysteine carboxyl methyltransferase (ICMT) as shown in Figure 1. ${ }^{7} \mathrm{H}$-Ras and K-Ras undergo additional palmitoylation modification. ${ }^{8}$ These post-translational modifications are necessary for binding to lipid membrane to execute their biologic functions.

The three-dimensional structures of Ras proteins with bound GTP and GDP and their mutant variants were determined through $\mathrm{X}$-ray crystallography in 1990. ${ }^{9-11}$ The Ras protein consists of a hydrophobic core of six $\beta$ sheets and five $\alpha$ helices that are interconnected by a series of 10 loops. Five of these loops determine the high-affinity nucleotide interactions of Ras and regulates GTPase activity. The GTP $\gamma$ phosphate is stabilized by interactions that are established with the residues Lys16, Tyr32, Thr35, Gly60, and 


\section{Figure 1: Post-translational Modification of Ras Protein at Carboxy Terminus}
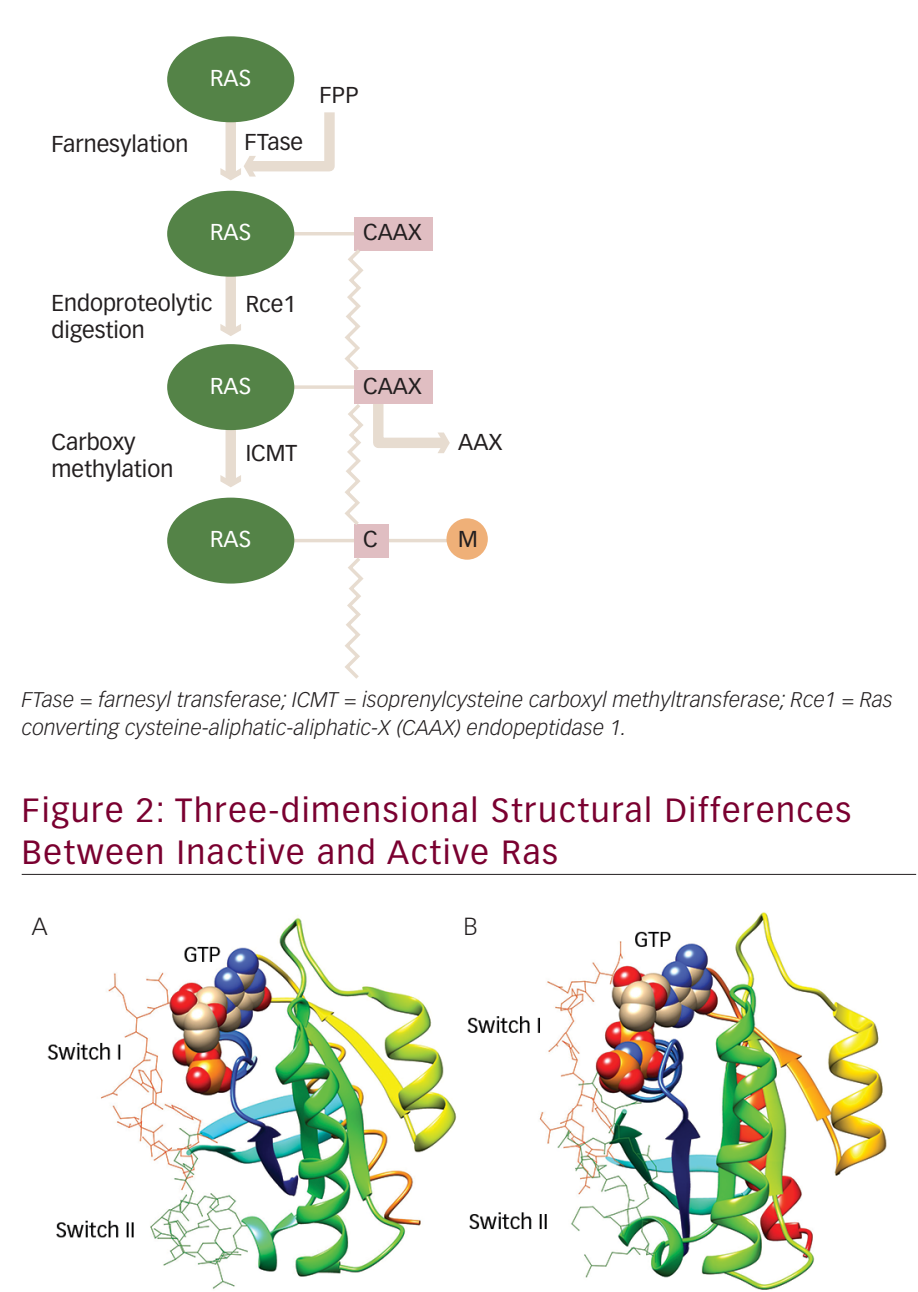

The three-dimensional structure of (A) inactive Ras (GDP-bound) (PDB ID:4Q21) and (B) active (GTP-bound) Ras protein (PDB ID:5P21). Both GDP as well as GTP are shown in spheres colored according to heteroatoms (oxygen: red; nitrogen: blue; carbon: tan; phosphorus: orange). Switch I (residues 30-40) and Switch II (residues 60-70) are represented in red and green wires, respectively, and the rest of the protein structure is displayed in ribbon. The structural difference between the inactive GDP-bound and the active GTP-bound Ras resides mainly in these two regions which are required for the interaction of Ras with its regulators and effectors. ${ }^{12}$

GIn61 of loops. GIn61 is a key residue that stabilizes the transition state of GTP hydrolysis to GDP, in addition to participating in the orientation of the nucleophilic attack that is necessary for this reaction. It has been seen that oncogenic mutations of Gln61 reduce the intrinsic GTP hydrolysis rate, thereby rendering the Ras protein constitutively active. The structural differences in GDP-bound Ras (inactive state) and GTP-bound Ras (active state) lies mainly in highly dynamic regions termed Switch I (residues 30-40) and Switch II (residues 60-70) as shown in Figure 2, which are required for the interaction of Ras with both upstream as well as downstream partners. The binding of GTP brings change in structural conformation of side chain of Switch I, via inward reorientation of side chain of Thr35, which facilitates its interaction with the GTP- $\gamma$ phosphate as well as the $\mathrm{Mg}^{2+}$ ion. Similarly, the $\gamma$-phosphate induces significant changes in the conformation of Switch II through the interaction it establishes with Gly60.12

Besides its normal function, such as cellular proliferation and differentiation, survival, and gene expression, gain-of function mutations of $\mathrm{H}-, \mathrm{N}-$, K-Ras have been found in different types of human cancers. ${ }^{12,13}$ Besides, aberrant Ras signaling is also implicated in several developmental disorders, known as the cardio-facio-cutaneous diseases (i.e., neurofibromatosis-type । [NF-1], Costello syndrome, and Noonan syndrome). ${ }^{14}$

The normal biological functioning of RAS proteins as described before require post-translational modification, guided by many important enzymes described earlier. These RAS preprocessing enzymes can serve as attractive drug targets. The activity of RAS is largely determined by the type of cofactors that it binds. When it is bound to GTP, it is active and can recruit downstream target proteins, but when it binds GDP, it is rendered inactive and fails to interact with the downstream effectors. This association of RAS with GTP or GDP is mediated by two enzymes: guanine nucleotide exchange factors (GEFS) and GTPase-activating proteins (GAPS). GEFSs catalyze the exchange of GDP for GTP whereas GAPs increase the rate of GTP hydrolysis to GDP plus phosphate. ${ }^{15}$

The activated RAS protein can bind and activate downstream effectors, which ultimately produce appropriate signals, such as cell proliferation, survival, and other physiological functions through the activation of various pathways (see Figure 3).

One of the first mammalian effector of RAS, which has been well studied and characterized is the protein serine/threonine kinase, is RAF.16,17 There are three closely related RAF proteins, CRAF1, BRAF, and ARAF, which are known to be activated by RAS-bound GTP. ${ }^{18}$ The activated RAF can phosphorylate and activate the downstream targets, such as mitogenactivated protein kinases 1 and 2 (MEK1 and MEK2). ${ }^{19}$ MEK1 and MEK2 can then phosphorylate and activate mitogen-activated protein kinases (MAPKS), such as extracellular signal-regulated kinases 1 and 2 (ERK1 and ERK2). The substrates for ERK1/2 include both nuclear as well as cytosolic proteins, of which transcription factors have been widely studied. ${ }^{20,21}$ ERK phosphorylate (ELK1) belongs to ETS family transcription factors, which, in turn, regulates the expression of FOS.22 Additionally, ERK can also phosphorylate c-JUN. ${ }^{23}$ The activation of all these transcription factors eventually promotes the cell cycle progression. ${ }^{24}$

In addition to the RAF/MAPK effector pathway, RAS can also interact with another well-characterized effectors ie., phosphatidyl inositol 3-kinases (PI3KS).25,26 The activated PI3KS phosphorylate phosphatidylinositol 4,5-bisphosphosphate (PtdIns(4,5)P2) produce a second messenger phosphatidylinositol-3,4,5-triphosphate(PtdIns(3,4,5)P3), which interacts with several other proteins through pleckstrin homology and other domains. ${ }^{27}$ Thus, PI3K exercises its control on a large number of downstream target proteins. PI3K regulates the activity of two important kinases PDK1 (3-phosphoinositide-dependent protein kinase-1) and AKT.28,29 PDK1 is important for the activation of many protein kinases of the AGC family, comprising AKT/PKB, p7056K, some PKCs and RSKS.30-33 AKT has an antiapoptotic function and have been found to be important for survival signals generated by RAS. ${ }^{34,35}$ Besides, PI3K activation also leads to the activation of RAC, a RHO family protein that not only regulates the actin cytoskeleton but also transcription factors, such as nuclear factor-kappa B( NF-KB). ${ }^{36-38}$ RAC activation also seems to be important in RAS-induced transformation. 39,40

The third well-known effector of RAS include three exchange factors for RAS-related RAL proteins: RAL guanine nucleotide dissociation stimulator 
(RALGDS), RGL2/RLF, RALGDS-like gene (RGL/RSB2). ${ }^{41-43}$ With the help of these proteins RAS is able to activate RAL, which in turn activates phospholipase D1, CDC42/RAC-GAP-RAL binding protein1 (RALBP1). ${ }^{44,45}$ These RALGDS pathway together with AKT contribute to the inhibition of FORKHEAD transcription factors. ${ }^{46}$ These have been involved in arresting cell cycle progression through activation of cyclin dependent kinase inhibitor, KIPI (also known as p27), and apoptosis through expression of the BIM and FAS ligands. ${ }^{47,48}$

Phospholipase $\mathrm{C}_{\varepsilon}$ is another effector of Ras. ${ }^{49}$ It hydrolysis phosphatidylinositol 4,5-bisphosphosphate to diacylglycerol and inositol-1,4,5-triphosphate, which leads to activation of PKC and calcium mobilization. ${ }^{50}$

Through the concerted efforts of RAS and its effectors, it is able to regulate a wide array of functions, such as cellular proliferation, survival, apoptosis, and other important physiological processes.

\section{Abnormal RAS Signaling in Tumors Activating Mutation in RAS}

The aberrant RAS signaling in tumors can be contributed by several different mutations, mostly activating mutation in tumor cells: $85 \%$ in K-RAS, $15 \%$ in N-RAS, and $<1 \%$ in H-RAS. Table 1 shows the frequency of RAS mutations in various human tumors. It is clear from Table 1 that significantly high rates of Ras mutation ( $>10 \%$ ) was found in tumors, such as colon (adenocarcinoma), leukemias (AML), lymphomas (Hodgkin's lymphoma), lung (large-cell carcinoma and non-small-cell carcinoma) and thyroid (anaplastic and folllicular carcinoma). It is also evident from Table 1 that the oncogenic mutation predominately affects the K-Ras locus, with oncogenic K-Ras mutations being detected ranging from 16 to $36 \%$ in various human tumors screened. The activating mutations mostly affect the GTPase activity of RAS leading to accumulation of RAS-bound GTP. ${ }^{51,52}$ These GTP-bound RAS can hyperactivate other downstream effector proteins previously discussed before leading to constitutive abnormal signaling and anarchy within the tumor cell. The impaired ability of Ras mutants to hydrolyze GTP, either intrinsically or in response to GAPS, is responsible for the oncogenic nature of mutations at residues $\mathrm{G} 12, \mathrm{G} 13$, and $\mathrm{Q} 61$ in the active site. ${ }^{53}$

\section{GAP Deletion}

Ras remains activated due to loss of GAP-accelerated GTP hydrolysis. One such typical example of GAP mutation is the GAPS, neurofibromin encoded by the NF1 tumor suppressor gene. ${ }^{54}$ Patients with neurofibromatosis type I inherit onlyone functional NF1 gene and then predisposed to cancer through complete loss of NF1.

\section{Growth Factor Receptor Activation}

Ras signaling has also been known to be activated in tumors in which growth factor receptor tyrosine kinase has been overexpressed. The most common example are epidermal growth factor receptor (EGFR) and receptor tyrosine-protein kinase erbB-2 (ERBB2) which are activated and overexpressed in many types of cancer including breast, ovarian, and stomach carcinomas. ${ }^{55}$

\section{Mutation or Amplification of Ras Effectors}

It has been found that BRAF is commonly activated by mutation in human tumors, such as melanomas and colon carcinoma. A study of 923 cancer samples reveal that missense mutations occur commonly in the BRAF
Figure 3: Ras Activation and Signaling Downstream of Ras

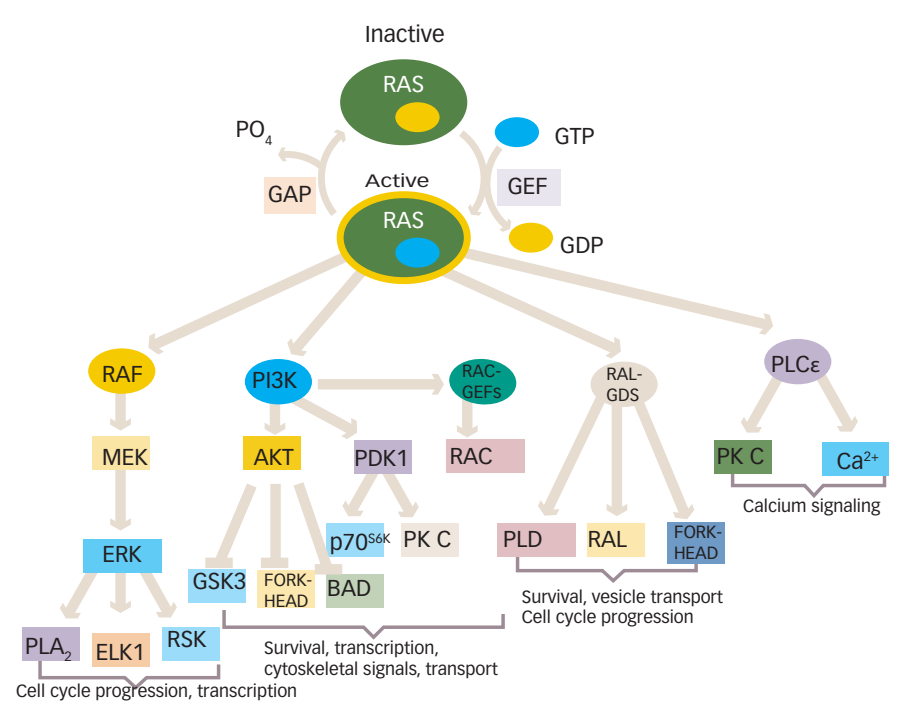

ERK = extracellular regulated kinase; GSK3 = glycogen synthase kinase $3 ;$ MEK = mitogenactivated kinase/ERK kinase; $P 70^{56 K}=p 70$ ribosomal protein S6 kinase; $P D K 1=$ phophatidyl triphosphate dependent kinase 1; $P I 3 K S=$ phosphoinositide-3 kinases; $P K C=$ protein kinase $C$; $P L A 2=$ phospholipase A2: $P L D=$ phopholipase $D ; R A L G D S$-guanine nucleotide exchange factors (GEFS) for RAL; RSK = p90 ribiosomal protein S6 kinase.

Table 1: Frequency of RAS Mutations in Human Tumors

\begin{tabular}{llllll}
$\begin{array}{l}\text { Serial } \\
\text { numberTissue }\end{array}$ & $\begin{array}{l}\text { Organ/ } \\
1\end{array}$ & Tumor type & H-RAS & N-RAS & K-RAS \\
\hline 2 & Cervix & Adenocarcinoma & $1(542)$ & $2(330)$ & $4(544)$ \\
\hline 3 & Colon & Adenocarcinoma & $0(76)$ & $2(55)$ & $36(4310)$ \\
\hline 4 & Ganglia & Neuroblastoma & $0(64)$ & $8(103)$ & $3(63)$ \\
\hline 5 & Leukemias & AML & $0(1216)$ & $12(3404)$ & $4(1778)$ \\
& & CML & $0(265)$ & $3(532)$ & $2(313)$ \\
\hline 6 & Lymphomas & Burkitt's lymphoma & $0(30)$ & $10(30)$ & $3(30)$ \\
& & Hodgkin's lymphoma & $2(44)$ & $16(45)$ & $0(44)$ \\
\hline 7 & Lung & Large-cell carcinoma & $4(50)$ & $4(49)$ & $21(189)$ \\
& & Non-small-cell carcinoma & $0(683)$ & $1(695)$ & $16(3575)$ \\
\hline 8 & Prostate & Adenocarcinoma & $6(489)$ & $2(509)$ & $8(1002)$ \\
\hline 9 & Stomach & Adenocarcinoma & $4(218)$ & $2(205)$ & $6(2054)$ \\
\hline 10 & Thyroid & Anaplastic carcinoma & $4(440)$ & $17(436)$ & $9(433)$ \\
& & Follicular carcinoma & $5(381)$ & $17(392)$ & $4(372)$
\end{tabular}

Values represented as total percentage of clinical samples analyzed and values in brackets indicate number of clinical samples analyzed. $A M L=$ acute myelogenous leukemia; $C M L=$ chronic myeloid leukemia. Data compiled from Sanger catalog of somatic mutations in cancer (available at: http://sanger.ac.uk/genetics/CGP/cosmic/).

gene in approximately $70 \%$ of human malignant melanoma and $15 \%$ of colorectal cancers. ${ }^{56}$ The major mutation found in tumors is V559E, a substitution of valine by glutamic acid, which occurs in the kinase activation domain resulting in activation of BRAF. ${ }^{56}$

The PI3K pathway is known to be activated due to amplification or mutation of PIK3CA encoding catalytic $\mathrm{p} 110 \alpha$ subunit of PI3K in ovarian and cervical tumors. ${ }^{57,58}$ These mutations commonly occur in two conserved regions of the gene, which encode the kinase and helical 
Table 2: Inhibitors Against Raf-MEK-ERK and PI3K-AKT Signaling under Clinical Investigation

\begin{tabular}{|c|c|c|c|c|c|}
\hline $\begin{array}{l}\text { S. } \\
\text { No. }\end{array}$ & $\begin{array}{l}\text { Therapeutic } \\
\text { Agents }\end{array}$ & Company & Target & Status & Target Population \\
\hline 1 & $\begin{array}{l}\text { BMS- } \\
908662 / \\
\text { XL281 }\end{array}$ & $\begin{array}{l}\text { Exesis/ } \\
\text { Bristol-Myers } \\
\text { Suibb }\end{array}$ & Raf & Phase I-II & $\begin{array}{l}\text { Alone or in combination } \\
\text { with cetuximab for } \\
\text { K-Ras or BRAF mutant } \\
\text { advanced or metastatic } \\
\text { CRC }\end{array}$ \\
\hline 2 & GSK2118436 & $\begin{array}{l}\text { GlaxoSmith } \\
\text { Kline }\end{array}$ & Raf & Phase I-II & $\begin{array}{l}\text { BRAF mutant melanoma } \\
\text { NSCLC and other solid } \\
\text { tumors }\end{array}$ \\
\hline 3 & AZD8330 & AstraZeneca & MEK1/2 & Phase I & Advanced malignancies \\
\hline 4 & $\begin{array}{l}\text { ARRY- } \\
\text { 438162/ } \\
\text { MEK162 }\end{array}$ & $\begin{array}{l}\text { Array } \\
\text { BioPharma/ } \\
\text { Novartis }\end{array}$ & MEK1/2 & Phase II & $\begin{array}{l}\text { BRAF or NRas mutant } \\
\text { metastatic melanomas; } \\
\text { advanced or metastatic } \\
\text { biliary cancer; metastatic } \\
\text { CRC }\end{array}$ \\
\hline 5 & E6201 & Eisai & MEK1/2 & Phase I & Advanced solid tumors \\
\hline 6 & $\begin{array}{l}\text { Selumetinib/ } \\
\text { AZD6244 }\end{array}$ & AstraZeneca & MEK1/2 & Phase III & $\begin{array}{l}\text { Locally advanced or } \\
\text { metastatic NSCLCS that } \\
\text { harbor mutations of } \\
\text { K-Ras }\end{array}$ \\
\hline 7 & BYL719 & Novartis & $\mathrm{PI} 3 \mathrm{~K} \alpha$ & Phase I & $\begin{array}{l}\text { Advanced PI3KCA } \\
\text { mutant solid tumors }\end{array}$ \\
\hline \multirow[t]{2}{*}{8} & CAL-101 & $\begin{array}{l}\text { Calistoga } \\
\text { Pharmaceuticals }\end{array}$ & PI3K & Phase I & $\begin{array}{l}\text { In combination with } \\
\text { therapeutic agents and } \\
\text { CD20 mAb in non- } \\
\text { Hodgkin's lymphoma } \\
\text { or chronic lymphocytic } \\
\text { leukemia }\end{array}$ \\
\hline & & & & Phase II & $\begin{array}{l}\text { In combination with } \\
\text { rituximab in leukemia } \\
\text { and lymphoma }\end{array}$ \\
\hline 9 & GSK2141795 & $\begin{array}{l}\text { Glaxosmith } \\
\text { Kline }\end{array}$ & AKT & Phase I & $\begin{array}{l}\text { Solid tumors and } \\
\text { lymphomas }\end{array}$ \\
\hline 10 & MK-2206 & Merck & AKT & Phase I & $\begin{array}{l}\text { In combination with } \\
\text { standard chemotherapy } \\
\text { in locally advanced or } \\
\text { metastatic solid tumors }\end{array}$ \\
\hline 11 & Perifosine & $\begin{array}{l}\text { AstaMedica, } \\
\text { Zentaris }\end{array}$ & AKT & Phase II & $\begin{array}{l}\text { In combination } \\
\text { with single-agent } \\
\text { chemotherapy in } \\
\text { metastatic cancer }\end{array}$ \\
\hline
\end{tabular}

CRC = colorectal cancer; NSCLCS = non-small-cell lung carcinoma. Data compiled from https://clinicaltrials.gov/

domains of the protein. These 'hot spot' mutations, H1047R, E545K, and E542K, are nonsynonymous missense mutations that confer constitutive kinase activity.59,60 Second mechanism of PI3K activation occurs by amplication of its downstream target AKT2 in ovarian and breast tumors. ${ }^{61}$ A somatic missense mutation in the pleckstrin homology $(\mathrm{PH})$ domain of AKT1 (E17K) had been identified in breast, colorectal, and ovarian cancers. ${ }^{62}$ Additionally, PI3K can be directly activated due to loss of tumor suppressor gene PTEN (phosphatase and tensin homolog deleted on chromosome ten). This gene encodes a lipid phospholipase that dephosphorylate phosphatidyl-3,4,5-triphosphate at position 3 of the inositol ring, which reverses the accumulation of these second messengers caused by PI3K and thus negatively regulates PI3K activity. PTEN is one of the most frequently mutated genes in human cancers. ${ }^{63,64}$

\section{Ras Inhibition Strategies}

The involvement of aberrant Ras signaling in different kinds of tumors in humans necessitates the development of therapeutic agents, which can restore a normal function in tumor cell. The developments of therapeutics against it have already started and some have successfully managed to enter into phase I-II clinical trials (see Table 2). Targetting the aberrant Ras signaling has largely come from indirect inhibition of Ras effectors, such as AKT, MEK-1/2, PI3K, Raf, etc. This Ras signaling inhibition strategies can be categorized into following four inhibition strategies (Figure 4); each one is discussed briefly below.

\section{Prevention of Ras-GTP Formation}

Early studies explored the potency of ATP-competitive kinase inhibitors, which were expected to be used for inhibiting nucleotide binding to Ras. Although the affinity of kinases for ATP are usually in the micromolar range, ${ }^{65}$ picomolar nucleotide affinities of Ras combined with millimolar intracellular nucleotide pools complicate the use of GTP-competitive inhibitors. ${ }^{66}$ Consequently, strategies that prevent the initial formation of the Ras-GTP complex were investigated.

Libraries of GTP analogs with alternations at the ribose or nucleotide moiety ${ }^{66}$ and of pyrazolo[3,4-b]quinoline ribosides ${ }^{67}$ yielded molecules with moderately increased affinity compared with GDP and relatively weak inhibitory potency.

\section{Covalent Locking of the GDP-bound State}

Because of the high affinity of Ras to GDP, nucleotide exchange requires assistance by GEF proteins such as Son of Sevenless (SOS) or the closely related RasGRF1 to facilitate GTP loading. Early examples of GEF inhibitors were identified from a compound library whose members were originally designed to compete with GDP for nucleotide binding. SCH53239 and its derivatives target a hydrophobic pocket close to the nucleotide binding site and inhibit the intrinsic nucleotide exchange. ${ }^{68,69}$ On the basis of these studies, a series of derivatives with improved potency and water solubility was designed that is capable of inhibiting the RasGRF1-catalyzed nucleotide exchange in vitro (half-maximum in hibitory concentration $[\mathrm{IC50}=35-320 \mu \mathrm{M}) .^{70,71}$ The orthosteric Ras-GEF interaction inhibitors described above do not discriminate between mutated and wild-type Ras. In an approach to overcome this limitation for mutated K-RasG12C, the thiol function of cysteine 12 was used to covalently trap inhibitors. A set of GDP-derived inhibitors was developed to directly target the nucleotide binding site. ${ }^{72}$ The most active compound, SML-8-73-1, covalently binds K-RasG12C even in the presence of millimolar concentrations of GDP and GTP. SML-1070-1 shows antiproliferative activity in Ras-dependent cells expressing K-RasG12C $($ EC50 $=27-47 \mu \mathrm{M}){ }^{73}$

Ostrem et al. ${ }^{74}$ reported covalent inhibitors that are selective for mutant cysteine over the wild type as it relies on trapping of the thiol group in Cys12 in common oncogenic mutant (K-Ras G12C) using disulphide- 
fragment-based screening approach. Binding of these inhibitors to K-Ras (G12C) destabilize the native nucleotide preference to favor GDP over GTP and impedes binding to Raf.

\section{Inhibition of Ras-effector Interactions}

Protein-protein interfaces (PPIS) between Ras-GTP and effectors initiate various downstream signaling cascades. Remarkably, Ras-GTP exists in at least two distinct conformational states, which interconvert with rate constants on the millisecond timescale. ${ }^{75}$ Whereas state 2 represents a conformation with high affinity for effector binding, the affinities for effectors exhibited in state 1 are reduced.76,77 However, state 1 exhibits surface cavities potentially accessible to small molecules that could stabilize this conformation and thereby inhibit interactions with effector proteins. $\mathrm{Zn}^{2+}$-cyclen, $\mathrm{Cu}^{2+-}$-cyclen, and bis(2-picolyl)amine complexes bind H-Ras-'GTP' with millimolar affinity and stabilize the 'noneffector binding' state $1 .{ }^{78,79}$ The feasibility of orthosteric Ras-effector interaction inhibition was shown with antibody fragments that block effector interaction sites of H-Ras-GTP. ${ }^{80}$ In this setup, disruption of mutant Ras-effector interactions is sufficient to prevent tumor initiation in a transgenic mouse model of lung cancer.81 Small peptide-based inhibitors lacking drug-like properties have been used to disrupt Raseffector interactions. ${ }^{82,83}$

\section{Impairment of Post-translational Modification of Ras}

Ras-dependent signaling requires the correct intracellular localization of Ras proteins predominantly at the plasma membrane, mediated by membrane-anchoring lipid residues at the $\mathrm{C}$ terminus. Therefore, impairment of Ras localization has been explored to inhibit oncogenic Ras signaling. ${ }^{84}$ Ras proteins are equipped with lipid groups through a series of post-translational modifications, which include cysteine S-farnesylation, proteolysis, and carboxymethylation at the $\mathrm{C}$ terminus of all Ras isoforms and additional cysteine S-palmitoylation of H-Ras and N-Ras. ${ }^{85}$

FarnesyltransfeRase inhibitors (FTIS) interrupt this biosynthetic sequence, leading to nonlipidated cytosolic Ras. Several FTIs reached late-stage clinical trials but ultimately failed, mostly because of alternative geranylgeranylation of the K-Ras and N-Ras isoforms. ${ }^{86}$ Treatment with
Figure 4: Four Categories of Ras Inhibition Strategies

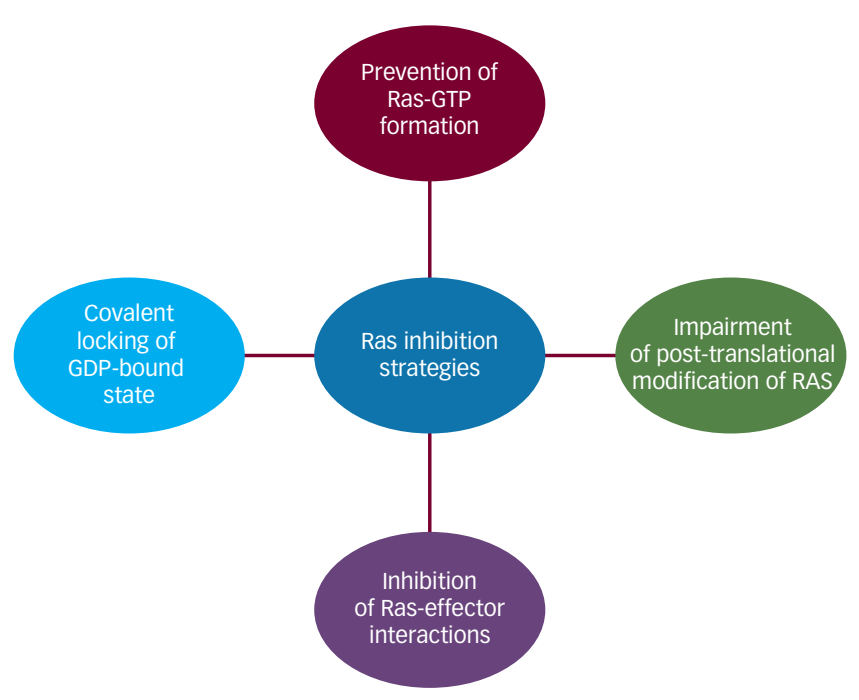

geranylgeranyl transfeRase inhibitors ${ }^{87}$ or dual prenylation inhibitors ${ }^{88}$ did not show clinical efficacy. However, a number of studies report promising preclinical and clinical results for FTIs as single agents or in combination with other conventional anticancer agents. ${ }^{89} \mathrm{FTIS}$ may also show positive clinical responses in the treatment of H-Ras-dependent cancers and tumors that rely on other farnesylated proteins for survival. ${ }^{87}$

\section{Conclusion}

Ras signaling pathways constitute central drivers of cancer development and therefore strategies have been sought for development of potent Ras inhibitors effective in vivo as well. Some inhibitors against Ras effectors such as Raf, MEK1/2, PI3K, AKT, etc. have already entered into clinical trials, which suggests the relevance of Ras signaling pathways in cancer therapeutics. Since Ras signaling pathway is a complex network controlled by several feedback loops, blocking a single pathway may not be adequate to achieve a reduction of Ras signaling to a therapeutically significant level. Therefore, combined therapies targeting Ras and other oncoproteins in parallel may be required to control tumors.
1. Rajalingam $K$, Schreck R, Rapp UR, et al., Ras oncogenes and their downstream targets, Biochim Biophys Acta, 2007:1773:1177-95.

2. Buday L, Downward J, Many faces of Ras activation, Biochim Biophys Acta, 2008;1786:178-87.

3. Rojas JM, Oliva JL, Santos E, Mammalian son of sevenless guanine nucleotide exchange factors: old concepts and new perspectives, Genes Cancer, 2011;2:298-305.

4. Vigil D, Cherfils J, Rossman KL, et al., Ras superfamily GEFs and GAPs: validated and tractable targets for cancer therapy? , Nat Rev Cancer, 2010:10:842-57.

5. Downward J, Targeting RAS signalling pathways in cancer therapy, Nat Rev Cancer, 2003;3:11-22.

6. Rubio I, Wittig U, Meyer C, et al., Farnesylation of Ras is important for the interaction with phosphoinositide 3-kinase gamma, Eur J Biochem, 1999; 266:70-82.

7. Tamanoi F, Hsueh EC, Goodman, LE, et al., Posttranslational modification of Ras proteins: Detection of a modification prior to fatty acid acylation and cloning of a gene responsible for the to fatty acid acylation and cloning of a gene respo

8. Dudler T, Gelb MH, Palmitoylation of Ha-Ras facilitates membrane binding, activation of downstream effectors, and meiotic maturation in xenopus oocytes, $\mathrm{J}$ Biol Chem, 1996;271:11541-7.

9. Brünger AT, Milburn MV, Tong L, et al., Crystal structure of an active form of RAS protein, a complex of a GTP analog and the HRAS p21 catalytic domain, Proc Natl Acad. Sci U S A the HRAS 21 cataly

10. Milburn MV, Tong L, deVos AM, et al., Molecular switch for signal transduction: structural differences between active and inactive forms of protooncogenic Ras proteins, science. 1990:247:939-45.

11. Schlichting 11 , Almo SC, Rapp G, et al., Time-resolved Xray crystallographic study of the conformational change in Ha-Ras p21 protein on GTP hydrolysis, Nature, 1990;345:309-15.

12. Karnoub $A E$, Weinberg RA, Ras oncogenes: split personalities, Nat Rev Mol Cell Biol, 2008;9:517-31.

13. Pylayeva-Gupta $Y$, Grabocka E, Bar-Sagi D, RAS oncogenes: weaving a tumorigenic web, Nat Rev Cancer, 2011:11:761-74.

14. Cox AD, Der CJ, Ras history: The saga continues, Small GTPases, 2010;1:2-27.

15. Quilliam LA, Khosravi-Far R, Huff SY, et al., Guanine nucleotide exchange factors: activators of the Ras superfamily of proteins, BioEssays, 1995;17:395-404

16. Moodie SA, Willumsen BM, Weber MJ, et al., Complexes of Ras GTP with Raf-1 and mitogen-activated protein kinase kinase, Science, 1993: 260:1658-61.

17. Warne $\mathrm{PH}$, Viciana PR, Downward J, Direct interaction of Ras and the amino-terminal region of Raf- 1 in vitro, Nature 1993;364:352-5

18. RoskoskiR Jr, RAF protein-serine/threonine kinases: structure and regulation, Biochem Biophys Res Commun, 2010;399:313-7.

19. Alessi DR, Saito Y, Campbell DG, et al., Identification of the sites in MAP kinase kinase-1 phosphorylated by p74raf-1, EMBO J, 1994;13:1610-9.

20. Yoon $\mathrm{S}$, Seger $\mathrm{R}$, The extracellular signal-regulated kinase: multiple substrates regulate diverse cellular functions, Growth Factors, 2006;24:21-44.
21. Murphy LO, Blenis J, MAPK signal specificity: the right place at the right time, Trends BiochemSci, 2006:31:268-75.

22. Cruzalegui $F H, C a n o E$, Treisman R, ERK activation induces phosphorylation of Elk-1 at multiple S/T-P motifs to high stoichiometry, Oncogene, 1999;18:7948-57.

23. Minden A, Lin A, Smeal T, et al., C-Jun N-terminal phosphorylation correlates with activation of the JNK subgroup but not the ERK subgroup of mitogen-activated protein kinases, $\mathrm{Mol}$ Cell Biol, 1994;14:6683-8.

24. Pruitt K, Der CJ, Ras and Rho regulation of the cell cycle and Pruitt K, Der CJ, Ras and Rho regulation of the

25. Rodriguez-Viciana P, Warne PH, Dhand R, et al., Phosphatidylinositol-3-OH kinase as a direct target of Ras, Nature, 1994;370:527-32.

26. Pacold ME, Suire $S$, Perisic $O$, et al., Crystal structure and functional analysis of Ras binding to its effector phosphoinositide 3-kinasey, Cell, 2000;103:931-43.

27. Milburn CC, Deak M, Kelly SM, et al., Binding of phosphatidylinositol 3,4,5-trisphosphate to the pleckstrin homology domain of protein kinase B induces a conformational change, Biochem J, 2003;375:531-8.

28. Alessi DR, Discovery of PDK1, one of the missing links in insulin signal transduction, Colworth Medal Lecture, Biochem SOC Trans, 2001;29:1-14.

29. Burgering BM, Coffer PJ, Protein kinase B (c-Akt) in phosphatidylinositol-3-OH kinase signal transduction, Nature, 1995:17:376:599-602.

30. Alessi DR, James SR, Downes $\mathrm{CP}$, et al., Characterization of a 3-phosphoinositide-dependent protein kinase which 
phosphorylates and activates protein kinase Balpha, Curr Biol, 1997:7:261-9.

31. Stokoe D, Stephens $L R$, Copeland $T$, et al., Dual role of phosphatidylinositol-3,4,5-trisphosphate in the activation of protein kinase B, Science, 1997;277:567-70.

32. Jensen CJ, Buch MB, Krag TO, et al., 90-kDa ribosomal S6 kinase is phosphorylated and activated by 3-phosphoinositidedependent protein kinase-1, J BiolChem, 1999;274:27168-76.

33. Richards SA, Fu J, Romanelli A, et al., Ribosomal S6 kinase 1 (RSK1) activation requires signals dependent on and independent of the MAP kinase ERK, Curr Biol, 1999:12:810-20.

34. Datta SR, Brunet A, Greenberg ME, Cellular survival: a play in three Akts, Genes Dev, 1999;13:2905-27.

35. Khwaja A, Rodriguez-Viciana P, Wennstroms, et al Matrix adhesion and Ras transformation both activate a phosphoinositide 3-OH kinase and protein kinase B/Akt cellular survival pathway, EMBO J, 1997;16:2783-93.

36. Welch HC, Coadwell WJ, Stephens LR, et al., Phosphoinositide 3-kinase-dependent activation of Rac, FEBS Lett, 2003;546:93-7.

37. Matos P, Collard JG, Jordan P, Tumor-related alternative spliced Rac1b is not regulated by Rho-GDI and exhibits selective downstream signaling, J Biol Chem, 2003;278:50442-8

38. Ridley AJ, Hall A, The small GTP-binding protein rho regulates the assembly of focal adhesions and actin stress fibers in response to growth factors, Cell, 1992;70:389-99.

39. Lambert JM, Lambert QT, Reuther GW, et al., Tiam1 mediates Ras activation of Rac by a PI(3)K-independent mechanism, Nature Cell Biol, 2002:4:621-5.

40. Malliri $A$, van der Kammen RA, Clark $K$, et al., Mice deficient in the Rac activator Tiam1 are resistant to Ras-induced skin tumours, Nature, 2002;417:867-71.

41. Hofer F, Fields S, Schneider C, et al., Activated Ras interacts with the Ral guanine nucleotide dissociation stimulator, Proc Nat Acad Sci U S A, 1994;91:11089-93.

42. Takaya A, Kamio T, Masuda M, et al., R-Ras regulates exocytosis by Rgl2/Rlf-mediated activation of RalA on endosomes, MOl Biol Cell, 2007:18:1850-60

43. Feig LA, Urano T, Cantor S, Evidence for a Ras/Ral signaling cascade, Trends Biochem Sci, 1996;21:438-41.

44. Frankel PM, Ramos J, Flom, S, et al., Ral and Rho-dependent activation of phospholipase D in v-Raf-transformed cells, BiochemBiophys Res Commun, 1999;255:502-7.

45. Jullien-Flores V, Dorseuil O, Romero F, et al., Bridging RalGTPase to Rho pathways. RLIP76, a Ral effector with CDC42/RacGTPaseactivating protein activity, J Biol Chem , $1995: 270: 22473-7$

46. De Ruiter ND, Burgering BM, Bos, JL, et al., Regulation of the Forkhead transcription factor AFX by Ral-dependent phosphorylation of threonines 447 and $451, \mathrm{Mol}$ Cell Biol, 2001;21:8225-35.

47. Medema RH, Kops GJ, Bos JL, et al., AFX-like forkhead transcription factors mediate cell-cycle regulation by Ras and PKB through p27kip1, Nature, 2000:404:782-7.

48. Nakamura N, Ramaswamy S, Vazquez F, et al., Forkhead transcription factors are critical effectors of cell death and cell cycle arrest downstream of PTEN, Mol Cell Biol, 2000;20:8969-82.

49. Kelley GG, Reks SE, Ondrako JM, et al., Phospholipase C (epsilon): a novel Ras effector, EMBO I, 2001:20:743-54.

50. Nishizuka Y, Intracellular signaling by hydrolysis of phospholipids and activation of protein kinase C, Science, 1992;258:607-14.

51. ManneV, Bekesi E, Kung HE, Ha-Ras proteins exhibit GTPase activity: point mutations that activate Ha-Ras gene products result in decreased GTPase activity, Proc Natl AcadSci U S A 1985;82:376-80.

52. Lin SR, Hsu CH, Tsai JH, et al., Decreased GTPase activity of $\mathrm{K}$-Ras mutants deriving from human functional adrenocortical tumours, Br J Cancer, 2000;82:1035-40.

53. Bos $\mathrm{JL}$, Ras oncogenes in human cancer: a review, Cancer Res, 1989;49:4682-9.

54. Weiss B, Bollag G, Shannon K, Hyperactive Ras as a therapeutic target in neurofibromatosis type 1, Am J Med Genet, 1999:89:14-22.

55. Mendelsohn J, Baselga J, The EGF receptor family as targets for cancer therapy, Oncogene, 2000;19:6550-65.

56. Davies $\mathrm{H}$, Bignell GR, Cox C,et al., Mutations of the BRAF gene in human cancer, Nature, 2002;417:949-54.

57. Shayesteh L, Lu Y, Kuo WL, et al., PI3K CA is implicated as an oncogenic in ovarian cancer, Nature Gent, 1999:21:99-102.

58. Ma YY, WeiSJ ,Lin YC et al., PIK3CA as an oncogene in cervica cancer, Oncogene, 2000;19:2739-44.

59. Samuels Y, Diaz Jr LA, Schmidt-Kittler O, et al., Mutant PIK3CA promotes cell growth and invasion of human cancer cells, Cancer Cell, 2005;7:561-73.

60. Samuels $Y$, Wang $Z$, Bardelli A, et al., High frequency of mutations of the PIK3CA gene in human cancers, Science, 2004;304:554.

61. Bellacosa A, de Feo D, Godwin AK, et al., Molecular alterations of the AKT2 oncogene in ovarian and breast carcinomas, Int Cancer, 1995;64:280-5.

62. Carpten JD, Faber AL, Horn C, et al., A transforming mutation in thepleckstrin homology domain of AKT1 in cancer, Nature, 2007;448:439-44.

63. Cantley LC, Neel BG, New insights into tumor suppression: PTEN suppresses tumor formation by restraining the phosphoinositide 3-kinase/AKT pathway Proc Natl Acad Sci U S A, 1999:96:4240-5

64. Simpson L, Parsons R, PTEN: life as a tumor suppressor, Exp Cell Res, 2001;264:29-41.

65. Becher I, Savitski MM, Savitski MF, et al., Affinity profiling of the cellular kinome for the nucleotide cofactors ATP, ADP, and GTP, ACS ChemBiol, 2013;8:599-607.

66. Noonan T, Brown N, Dudycz L, et al., Interaction of GTP derivatives with cellular and oncogenic Ras-p21 proteins, I Med Chem 1991:34:1302-7.

67. Wolin R, Wang D, Kelly J, et al., Synthesis and evaluation of pyrazolo[3,4-b]quinolineribofuranosides and their derivatives as inhibitors of oncogenic Ras, Bioorg Med Chem Lett, 1996;6:195-200

68. John J, Rensland H, Schlichting I, et al., Kinetic and structural analysis of the Mg2+-binding site of the guanine nucleotidebinding protein p21H-Ras, I Biol Chem, 1993;268:923-9.

69. Taveras AG, Remiszewski SW, Doll RJ, et al., Rasoncoprotein inhibitors: the discovery of potent, Ras nucleotide exchange inhibitors and the structural determination of a drug-protein complex, Bioorg Med Chem, 1997; 5:125-33.

70. Ganguly AK, Wang YS, Pramanik BN, et al., Interaction of a nove GDP exchange inhibitor with the Ras protein, Biochemistry, 1998; $37: 15631-7$

71. Peri F, Airoldi C, Colombo S, et al., Design, synthesis and biological evaluation of sugar-derived Ras inhibitors, Chem Bio Chem, 2005;6:1839-48.

72. Sacco E, Abraham SJ, Palmioli, A et al., Binding properties and biological characterization of new sugar-derived Ras ligands, Med Chem Commun, 2011;2:396-401.

73. Hunter JC, Gurbani D, Ficarro SB, et al., In situ selectivity profiling and crystal structure of SML-8-73-1, an active site inhibitor of oncogenic K-Ras G12C, Proc Natl Acad Sci U S A, 2014;111:8895-900

74. Ostrem, JM, Peters U, Sos ML, et al., K-Ras(G12C) inhibitors allosterically control GTP affinity and effector interactions, Nature, 2013:503:548-51

75. Geyer M, Schweins T, Herrmann C, et al., Conformational transitions in p21 Ras and in its complexes with the effector protein Raf-RBD and the GTPase activating protein GAP, Biochemistry, 1996;35:10308-20.

76. Spoerner M, Herrmann C, Vetter IR, et al., Dynamic properties of the Ras switch I region and its importance for binding to effectors, Proc Natl Acad Sci U S A, 2001:98:4944-9.

77. Spoerner M, Wittinghofer A, Kalbitzer HR, Perturbation of the conformational equilibria in Ras by selective mutations as studied by 31P NMR spectroscopy, FEBS Lett, 2004;578:305-10.

78. Rosnizeck IC, Graf T, Spoerner M, et al., Stabilizing a weak binding state for effectors in the human Ras protein by cyclen complexes, Angew Chem Int Ed Engl, 2010;49:3830-3.

79. Rosnizeck IC, Spoerner M, Harsch T, et al., Metal-bis(2-picolyl) amine complexes as state 1(T) inhibitors of activated Ras protein, Angew Chem Int Ed Engl, 2012:51:10647-51.

80. Tanaka T, Williams RL, Rabbitts TH, Tumour prevention by a single antibody domain targeting the interaction of signal transduction proteins with RAS, EMBO J, 2007;26:3250-9.

81. Tanaka T, Rabbitts TH, Interfering with RAS-effector protein interactions prevent RAS-dependent tumour initiation and causes stop-start control of cancer growth, Oncogene, 2010:29:6064-70

82. Barnard D, Sun H, Baker, L, et al., In vitro inhibition of Ras-Raf association by short peptides, Biochem Biophys Res Commun, 1998;247:176-80

83. Wu X, Upadhyaya P, Villalona-Calero MA, et al., Inhibition of Raseffector interactions by cyclic peptides, Med Chem Commun, 2013;4:378.

84. Baines AT, XU D, Der CJ, et al., Inhibition of Ras for cancer treatment: the search continues, Future Med Chem, 2011:3:1787-808

85. Ahearn IM, Haigis K, Bar-Sagi D, et al., Regulating the regulator: post-translational modification of RAS, Nat Rev Mol Cell Biol, 2012;13:39-51

86. Whyte DB, Kirschmeier P, Hockenberry TN, et al., K- and N-Ras are geranylgeranylated in cells treated with farnesyl protein transferase inhibitors, J Biol Chem, 1997;272:14459-64.

87. Berndt N, Hamilton, AD, Sebti, SM, Targeting proteinprenylation for cancer therapy, Nat Rev Cancer, 2011;11:775-91.

88. Lobell RB, Liu D, Buser CA et al., Preclinical and clinical pharmacodynamic assessment of $1-778,123$, a dual inhibitor of farnesyl:protein transferase and geranylgeranyl:protein transferase type-I, Mol Cancer Ther, 2002;1:747-58

89. Wang Y, Kaiser CE, Frett B, et al., Targeting mutant KRAS for anticancer therapeutics: a review of novel small molecule modulators, I Med Chem, 2013:56:5219-30.. 